\title{
Lower attendance rates in BreastScreen Norway among immigrants across all levels of socio-demographic factors: a population-based study
}

\begin{abstract}
Background: Several studies have shown that immigrants attend mammographic screening less frequently than non-immigrants. Studies have also shown that attendance is influenced by socio-demographic factors. We aimed to describe the relationship between socio-demographic factors and first attendance among immigrant and nonimmigrant women invited to BreastScreen Norway.

Methods: Our cohort consisted of 885,979 women invited to BreastScreen Norway for their first time between 1996 and 2015. We merged individual level socio-demographic data to attendance data corresponding to women's first invitation to the program. Using Poisson regression, we calculated rate ratios with $95 \%$ confidence intervals ( $95 \% \mathrm{CI}$ ) for attendance, stratified by region of origin. Covariates of interest included age, income, education level, employment status, marital status, citizenship and years since immigration, among others.
\end{abstract}

Results: $53 \%$ of immigrants and $76 \%$ of non-immigrants attended mammographic screening after their first invitation; immigrants as a whole had lower attendance rates across all socio-demographic factors. However, the association between socio-demographic factors and attendance varied between immigrant groups. For all immigrants, no recorded education demonstrated the strongest association with non-attendance, compared to $\leq$ 10 years recorded education $\left(\mathrm{RR}_{\text {adj }}: 0.69,95 \% \mathrm{CI}\right.$ : $\left.0.67-0.71\right)$. Other factors associated with non-attendance were low income, living in Oslo, not being employed and being a recent immigrant.

Conclusion: The association between socio-demographic factors and mammographic screening attendance differed between immigrant groups. Further studies and preventive health measures should take into account that considering immigrants as a homogenous group may lead to less effective interventions.

Keywords: Breast Cancer, Ethnicity, Health Inequalities, Screening, Migration 


\section{Introduction}

Breast cancer is the most common cancer and the leading cause of cancer death among women worldwide (Ferlay et al. 2015). However, breast cancer incidence and mortality rates vary greatly across the world (Ferlay et al. 2015). While incidence rates are lowest in Africa and Asia, mortality rates are highest in Africa (Ferlay et al. 2015). Disparities in breast cancer mortality may be related to the availability of diagnostics and treatment, and access to screening (World Health Organization 2018).

Over the past decades, many high-income countries have implemented mammographic screening as a strategy to reduce breast cancer mortality (Youlden et al. 2012). The rationale behind mammographic screening is to detect breast cancer at an early stage requiring less advanced treatment and thereby reduce morbitidy and mortality from the disease (Lauby-Secretan et al. 2015; Marmot et al. 2013). A high attendance rate is necessary to reduce breast cancer mortality through organized mammographic screening; the European guidelines indicate that an attendance rate of $70 \%$ is acceptable and $75 \%$ is desirable (Perry et al. 2008).

Low income, lack of health insurance, and other socio-demographic factors have been associated with screening attendance below recommended levels given in the European guidelines (Perry et al. 2008; Schueler et al. 2008; Zackrisson et al. 2004). In particular, studies from Europe, North America, and Oceania have identified disproportionately low attendance among immigrants compared with non-immigrants (Bhargava et al. 2018). Additionally, some groups of immigrant women are more likely to be diagnosed with more advanced disease and thus experience higher rates of breast cancer mortality (Latif et al. 2015; Thøgersen et al. 2017).

Increasing international migration makes socio-demographic disparities in access to, and outcomes from, screening among immigrants a topical issue. However, many studies lack information about immigration status or make use of self-reported data (Berens et al. 2014; Weber et al. 2014). Immigrant women represent highly heterogeneous groups in terms of pre-migratory, historical, cultural, and economic circumstances. They may therefore have varying socio-demographic characteristics that could differentially influence screening attendance when compared to other immigrant groups, non-immigrants, and second generation immigrants. This makes it important to investigate attendance among groups of immigrants.

Overall screening attendance rates are higher in the Scandinavian countries than many other countries offering organized mammographic screening (International Cancer Screening Network 2016). The annual attendance rate in BreastScreen Norway is about 75\% (Sebuodegard et al. 2016). However, we have observed that immigrants have an attendance rate that is 23 percentage points lower than non-immigrants' after their first invitation to the program, $76 \%$ versus 53\% (Bhargava et al. 2017).

All inhabitants in Norway are assigned an unique personal identification number (PIN) (The Norwegian Tax Administration 2018). Women targeted by BreastScreen Norway are identified through their PIN, and the PIN allows us to link individual screening data from the Cancer Registry of Norway with socio-demographic data from Statistics Norway. In this study, we took advantage of individually linked data to identify the extent to which socio-demographic factors were associated with attendance among immigrant and non-immigrant women invited to the program during the period 1996 to 2015. 


\section{Materials and methods}

BreastScreen Norway started in 4 of 19 Norwegian counties in 1996 . The program expanded gradually, covering all 19 counties by 2005 . All women born in birth cohorts corresponding to age 50 to 69 at the start of a screening round receive an invitation every two years by a personal letter stating a time and place for examination. Screening takes place at stationary units in populated areas, whereas mobile units serve many rural areas. Non-attending women receive a reminder letter 4-8 weeks after their scheduled appointment. The attendance rate is $70 \%$ after initial invitations, increasing to $75 \%$ after reminders are sent. Women pay a user fee of 240 NOK (about $€ 30$ ) to gain access to screening and any required recall and diagnostic work-up (The Norwegian Breast Cancer Screening Program 2017).

The Regional Committees for Medical and Health Research Ethics (REC 2013/795) approved this study.

\section{Data sources and variables}

Our study population included 885,979 women with no history of breast cancer who received their first invitation to the program between 1996 and 2015. The Cancer Registry of Norway registers information about all cancers diagnosed in Norway, as well all information about screening invitations and attendance in BreastScreen Norway (The Norwegian Breast Cancer Screening Program 2017). We extracted information regarding women's attendance after their first invitation to the screening program, as well as information about breast cancer history from the Cancer Registry of Norway's databases. We merged data from the Cancer Registry with information about date of birth and death, and socio-demographic factors (county of residence, country of birth, immigration, emigration, income, net worth, education level, employment status, disability benefit recipient status, marital status, and citizenship) from Statistics Norway, using the women's PIN.

Information about age, county of residence, screening year, and years since immigration refer to the date of the scheduled screening appointment. Income, net worth, employment status, and disability benefit recipient status refer to values from the year prior to the appointment. Employment status was not available prior to 2001. Education level, marital status, and citizenship refer to the most recent values available. Income and net worth were categorized into deciles derived from all women aged 25 to 67 in order to exclude values from students and pensioners.

We adopted Statistics Norway's definition of immigrants: persons born abroad with two foreign-born parents and four foreign-born grandparents (Statistics Norway 2017b). All other women were defined as nonimmigrants. Our approach to selecting appropriate geographical divisions to represent region of origin was twofold. First, we considered the United Nations' (U.N.) Population Division of regions as an unbiased geographical division. Secondly, we modified these 23 regions to create 9 regions ("Norway", "Western Europe", "The Baltic Countries", "Southern \& Eastern Europe", "Northern Africa \& Western Asia”, "Eastern Africa", "Rest of Africa", "Rest of Asia" and "The Americas \& the Pacific"), based on political, historical and cultural similarities, geographical proximity and similar screening rates for women born in these regions (Appendix).

\section{Statistical analysis}


We performed descriptive statistics of attendance rates stratified by region of origin for the following sociodemographic factors: age, income, net worth, education level, employment status, disability benefit recipient status, marital status, citizenship, place of residency, screening year, and years since immigration. Further, we calculated unadjusted and adjusted rate ratios ( $R R$ and $R_{\text {adj }}$, respectively) with $95 \%$ confidence intervals (95\% CI) using Poisson regression with robust variance to assess the relationship between attendance and these sociodemographic factors, stratified by region. In total, there were 11 multivariate models: one for all women, one for non-immigrants, one for immigrants, and one for each of the eight regions of origin. Additionally, we used unadjusted rate ratios to compare immigrants' and non-immigrants' attendance rates for each socio-demographic factor. We created a dummy level to represent missing employment status information prior to 2001 . We assessed pairwise associations between covariates of interest to examine collinearity. All observed coefficients of determination $\left(\mathrm{R}^{2}\right)$ were $\leq 0.25$. We used Stata MP version 15.0 for all analyses.

\section{Results}

The study cohort consisted of 885,979 women, 72,207 of whom were immigrants (Table 1). The largest group of immigrants came from Western Europe $(n=24,509)$, followed by Rest of Asia $(n=18,169)$, and Southern \& Eastern Europe $(n=14,913)$ (Appendix Table 1). Immigrants were more likely than non-immigrants to have an income in the lowest decile (28\% versus $8 \%$ ). Among immigrants, those from Nothern Africa \& Western Asia and The Baltic Countries were most likely to have an income in the lowest decile (42\% and 39\%, respectively). A higher proportion of immigrants had no recorded education compared to non-immigrants (17\% versus $1 \%)$. A total of $26 \%$ of immigrants were living in the capital city of Oslo compared to $11 \%$ of non-immigrants.

Immigrants from the Baltic Countries had the lowest proportion living in Oslo (8\%).

Among all women, we observed a lower crude attendance rate among those with no recorded education, who were unemployed, or who lived in Oslo (Table 2). Immigrants had lower attendance rates than non-immigrants across all levels of socio-demographic factors (Figure 1 and Table 2). Women from most regions had lower attendance if they were not married, $25 \%-56 \%$ for immigrants and $66 \%$ for non-immigrants. For all immigrant groups, income in the lowest decile was associated with low attendance, ranging from $25 \%$ to $52 \%$, compared to $71 \%$ for non-immigrants in the lowest income decile. We did not observe a similar finding for net worth. Overall, screening attendance was 57\% among immigrants receiving disability benefits and 53\% among immigrants not receiving such benefits. We observed the opposite among non-immigrants and immigrants from Rest of Africa (70\% and $78 \%$, and $46 \%$ and $54 \%$, respectively, for those receiving disability benefits versus those not receiving benefits). For most immigrant groups, the attendance rate increased with years since immigration.

Generally, the risk ratios for attendance were higher in the univariate models. Discrepancies between the univariate and multivariate models were more pronounced for immigrants than non-immigrants (Table 3, Table 4 and Appendix Table 2). For all women combined, the strongest association was observed between education and attendance $\left(\mathrm{RR}_{\mathrm{adj}} 0.61,95 \% \mathrm{CI} 0.60\right.$ - 0.62 for no recorded education versus less than 10 years) (Table 3 ).

Having an income in the lowest decile, not being employed, being separated or not married, having foreign citizenship, or living in Oslo were also associated with lower risk of attendance among all women combined. With the exception of citizenship for immigrants, the abovementioned associations persisted when stratified into 
non-immigrants and all immigrants. The magnitudes of the adjusted risk ratios were similar for non-immigrants and all immigrants, however income was more strongly associated with attendance among immigrants.

The association between socio-demographic factors and attendance among immigrants varied when stratified by region of origin (Table 4). Having an income in the lowest decile was associated with lower attendance for most groups. Being unemployed compared with being employed, was associated with statistically significantly lower attendance for women from Western Europe, Eastern Africa, and Rest of Asia. The RR $\mathrm{R}_{\text {adj }}$ for attendance among women from Eastern Africa not receiving disability benefits compared to those receiving these benefits was $0.74,95 \%$ CI $0.61-0.89$. Further, living outside Oslo was associated with increased attendance among immigrants overall. This relationship was observed in the stratified models but did not reach statistical significance for women from the Baltic Countries and Rest of Africa. The majority of recent immigrants had lower attendance than immigrants who had been in Norway for at least ten years, except for immigrants from Eastern Africa, where the opposite was observed.

\section{Discussion}

In this study of 885,979 women with no history of breast cancer invited to organized mammographic screening in Norway, we observed lower attendance rates among immigrants than non-immigrants, across all levels of the socio-demographic factors studied. These rates varied for immigrants from different regions and by sociodemographic factors.

Compared to $\leq 10$ years of education, no recorded education demonstrated the strongest and most consistent negative association with attendance for women from all regions, both for immigrants and non-immigrants. Our findings indicate that women with no recorded education might form a particularly vulnerable group that may need increased attention when planning information activities and interventions regarding screening attendance. If no record of education represents no education, possible explanations for lower attendance could include particular health, social and/or economical circumstances that negatively influenced women's ability to follow a school system and thereby understand written information in Norwegian, including screening invitations, or the ability to prioritize screening .

We also found that living in Oslo was associated with lower attendance for most women. This is consistent with results from other studies analyzing attendance rates among women residing in urban versus rural areas (National Health Service 2017). Urban areas such as Oslo typically have larger immigrant populations, more women with higher education, and increased access to opportunistic screening - all factors that could negatively affect attendance at organized screening. Indeed, we observed a higher proportion of immigrants and women with higher education in Oslo than other parts of Norway. However, little is known about opportunistic screening attendance in Norway, and this information was not available for our study. More research is needed to understand how urban settings influence attendance. 
Lower attendance rates were observed among women who had an income in the lowest decile, or who were unemployed, compared with those with higher income or who were employed, respectively. Our findings are in line with results from other studies reporting an association between low income or unemployment and low attendance (Lagerlund et al. 2002; Vahabi et al. 2016). Financial and/or social concerns might reduce the opportunity to prioritize time or money for screening. Although the user fee for mammographic screening in Norway may be considered affordable, women with a low income or women who are unemployed might not prioritize spending their money on screening. We observed also that the relationship between income and screening attendance was more pronounced among immigrants than non-immigrants, suggesting that income is likely a stronger determinant of screening attendance among immigrants than non-immigrants.

As with studies from other countries (Schueler et al. 2008; Vahabi et al. 2016) our study showed that recent immigration (less than five years) was associated with lower attendance for women from most regions. This might indicate that immigrants who have resided longer in a country are more likely to make use of the public services in that country, including health services such as mammographic screening. However, we did not observe this effect among women from Eastern Africa. Women from Eastern Africa also differed from the other immigrant groups with respect to the association between not receiving disability benefits and attendance, as shown by the $\mathrm{RR}_{\mathrm{adj}}$. In our study population, women from Somalia represent a substantial proportion of the Eastern Africa group (44.3\%). Somalis in Norway have lower income (52\% of the median income in Norway, SSB 2009 - 2016) (Statistics Norway 2017d) and employment levels (32.4\% in 2015) (Statistics Norway 2017a) than immigrants and non-immigrants alike. They also have the lowest screening attendance rates (Bhargava et al. 2017). As a result, this group may benefit from a targeted approach when planning interventions to increase attendance among immigrants.

Our results demonstrated that immigrants attended screening less often than non-immigrants and further demonstrated that some socio-demographic factors may have a stronger influence on immigrants' attendance at BreastScreen Norway than non-immigrants. Immigrants might face extra challenges navigating health care services due to unfamiliarity with these services, or linguistic or cultural differences. Norredam et al. reviewed the access to health care services among immigrants in Europe and found a trend towards lower attendance at screening services among immigrants than non-immigrants (Norredam et al. 2009). Similarly, a recent study found lower attendance rates for immigrants than non-immigrants in the Norwegian cervical cancer screening program (Leinonen et al. 2017). These findings support the hypothesis that the screening disparity observed in this study may be due to systematic health access challenges associated with having an immigrant background.

We did not have information about factors pertaining to linguistic or cultural backgrounds, or to pre-migratory factors among women in our study. Understanding how these factors influence screening attendance could be important. For instance, the gender of the radiographer performing the mammogram might consistute a barrier against attendance. Additionally, our analyses were limited by not having information about reasons for immigration. Reasons for immigration differ between and within immigrant groups (Statistics Norway 2017c). If reasons for immigration affect screening attendance, this could be a source of residual confounding in our study. 
Such confounding could also be caused by other socio-demographic factors we did not have access to, such as traveling distance to the screening unit (Maheswaran et al. 2006), or use of opportunistic screening.

In conclusion, we observed that immigrants had lower attendance at BreastScreen Norway than non-immigrants, across all levels of the socio-demographic factors studied. Moreover, we observed that women's region of origin influenced the effect of the socio-demographic factors on attendance. For the majority of immigrant groups, no recorded education, low income, living in Oslo, not being employed, or being a recent immigrant were associated with lower attendance. Further studies investigating socio-demographic factors, as well as linguistic, cultural and pre-migratory circumstances, are needed to improve the inclusivity of organized mammographic screening. 
Acknowledgements: This study was supported by a grant from the Norwegian Breast Cancer Society, funded by the Norwegian ExtraFoundation for Health and Rehabilitation (2016/FO76429)

(https://www.extrastiftelsen.no/logo/). The funding source had no involvement in the conduction of the study, interpretation of the results or preparation of the manuscript.

Ethical approval: The Regional Committees for Medical and Health Research Ethics (REC 2013/795) approved this study.

Funding: This study was supported by a grant from the Norwegian Breast Cancer Society, funded by the Norwegian ExtraFoundation for Health and Rehabilitation (2016/FO76429)

(https://www.extrastiftelsen.no/logo/). The funding source had no involvement in the conduction of the study, interpretation of the results or preparation of the manuscript.

Conflicts of interest: The authors declare that they have no conflicts of interest. 


\section{References}

Berens EM, Stahl L, Yilmaz-Aslan Y, Sauzet O, Spallek J, Razum O (2014) Participation in breast cancer screening among women of Turkish origin in Germany - a register-based study. BMC Women's Health 14:24. doi:10.1186/1472-6874-14-24

Bhargava S, Moen K, Qureshi SA, Hofvind S (2018) Mammographic screening attendance among immigrant and minority women: a systematic review and meta-analysis. Acta Radiol 0:0284185118758132. doi:10.1177/0284185118758132

Bhargava S, Tsuruda K, Moen K, Bukholm I, Hofvind S (2017) Lower attendance rates in immigrant versus non-immigrant women in the Norwegian Breast Cancer Screening Programme. J Med Screen:0969141317733771

Ferlay J, Soerjomataram I, Dikshit R, Eser S, Mathers C, Rebelo M, Parkin DM, Forman D, Bray F (2015) Cancer incidence and mortality worldwide: sources, methods and major patterns in GLOBOCAN 2012. Int J Cancer 136:E359-E386

International Cancer Screening Network (2016) National Cancer Institute. Breast Cancer Screening Programs in 26 ICSN Countries, 2012: Organization, Policies, and Program Reach. 2 December 2016. http://healthcaredelivery.cancer.gov/icsn/breast/screening.html. Accessed 11 January 2018

Lagerlund M, Maxwell AE, Bastani R, Thurfjell E, Ekbom A, Lambe M (2002) Sociodemographic predictors of non-attendance at invitational mammography screening-a population-based register study (Sweden). Cancer Causes and Control 13:73-82

Latif F, Helgeland J, Bukholm G, Bukholm IRK (2015) Ethnicity differences in breast cancer stage at the time of diagnosis in Norway. Scand J Surg 104:248-253. doi:10.1177/1457496914565420

Lauby-Secretan B, Scoccianti C, Loomis D, Benbrahim-Tallaa L, Bouvard V, Bianchini F, Straif K (2015) Breast-cancer screening--viewpoint of the IARC Working Group. N Engl J Med 372:2353-2358. doi:10.1056/NEJMsr1504363

Leinonen MK, Campbell S, Ursin G, Tropé A, Nygård M (2017) Barriers to cervical cancer screening faced by immigrants: a registry-based study of 1.4 million women in Norway. Eur J Public Health 27:873-879

Maheswaran R, Pearson T, Jordan H, Black D (2006) Socioeconomic deprivation, travel distance, location of service, and uptake of breast cancer screening in North Derbyshire, UK. J Epidemiol Community Health 60:208-212

Marmot MG, Altman DG, Cameron DA, Dewar JA, Thompson SG, Wilcox M, The Independent UKPoBCS (2013) The benefits and harms of breast cancer screening: an independent review: A report jointly commissioned by Cancer Research UK and the Department of Health (England) October 2012. Br J Cancer 108:2205-2240. doi:10.1038/bjc.2013.177

National Health Service (2017) Breast Screening Programme - England, 2015-2016: Report. Report, National Health Service Digital, United Kingdom.

Norredam M, Nielsen SS, Krasnik A (2009) Migrants' utilization of somatic healthcare services in Europe-a systematic review. Eur J Public Health 20:555-563

The Norwegian Breast Cancer Screening Program (2017), 1996-2016: Celebrating 20 years of organised mammographic screening. Cancer in Norway 2016 - Cancer incidence, mortality, survival and prevalence in Norway. Report. Cancer Registry of Norway, Oslo, Norway.

The Norwegian Tax Administration (2018) National ID number. http://www.skatteetaten.no/en/person/National-Registry/Birth-and-nameselection/Children-born-in-Norway/National-ID-number/. Accessed 11 January 2018

Perry N, Broeders M, de Wolf C, Törnberg S, Holland R, von Karsa L (2008) European guidelines for quality assurance in breast cancer screening and diagnosis. Fourth edition-summary document. Ann Oncol 19:614-622. doi:10.1093/annonc/mdm481 
Schueler KM, Chu PW, Smith-Bindman R (2008) Factors associated with mammography utilization: a systematic quantitative review of the literature. J Womens Health (Larchmt) 17:1477-1498

Sebuodegard S, Sagstad S, Hofvind S (2016) [Attendance in the Norwegian Breast Cancer Screening Programme] Tidsskr Nor Laegeforen 136:1448-1451. doi:10.4045/tidsskr.15.1013

Statistics Norway (2017a) Employment among immigrants, register-based. 30 March 2017. http://www.ssb.no/en/arbeid-og-lonn/statistikker/innvregsys. Accessed 11 January 2018

Statistics Norway (2017b) Immigrants and Norwegian-born to immigrant parents. 2 March 2017. https://www.ssb.no/en/innvbef. Accessed 12 January 2018

Statistics Norway (2017c) Reasons for immigration. 19 June 2017. https://www.ssb.no/en/innvgrunn/. Accessed 12 January 2018

Statistics Norway (2017d) Table 10489: Immigrants' after-tax income per consumption unit, by country of origin 2009 - 2016. http://www.ssb.no/en/statbank/table/10489/?rxid=8fcfbc059fd7-469b-b9ca-3291f64f7415. Accessed 11 January 2018

Thøgersen H, Møller B, Robsahm TE, Aaserud S, Babigumira R, Larsen IK (2017) Comparison of cancer stage distribution in the immigrant and host populations of Norway, 1990-2014. Int J Cancer 141:52-61

Vahabi M, Lofters A, Kumar M, Glazier RH (2016) Breast cancer screening disparities among immigrant women by world region of origin: a population-based study in Ontario, Canada. Cancer Med 5:1670-1686

Weber MF, Chiew M, Feletto E, Kahn C, Sitas F, Webster L (2014) Cancer Screening among Immigrants Living in Urban and Regional Australia: Results from the 45 and Up Study. Int J Environ Res Public Health 11:8251-8266. doi:10.3390/ijerph110808251

World Health Organization (2018) Breast cancer: prevention and control. http://www.who.int/cancer/detection/breastcancer/en/index1.html. Accessed 11 January 2018

Youlden DR, Cramb SM, Dunn NAM, Muller JM, Pyke CM, Baade PD (2012) The descriptive epidemiology of female breast cancer: An international comparison of screening, incidence, survival and mortality. Cancer Epidemiol 36:237-248. doi:https://doi.org/10.1016/j.canep.2012.02.007

Zackrisson S, Andersson I, Manjer J, Janzon L (2004) Non-attendance in breast cancer screening is associated with unfavourable socio-economic circumstances and advanced carcinoma. Int J Cancer 108:754-760 
Table 1: Socio-demographic characteristics of women invited to attend BreastScreen Norway, 1996-2015 (see Appendix Table 1 for characteristics stratified by region of origin).

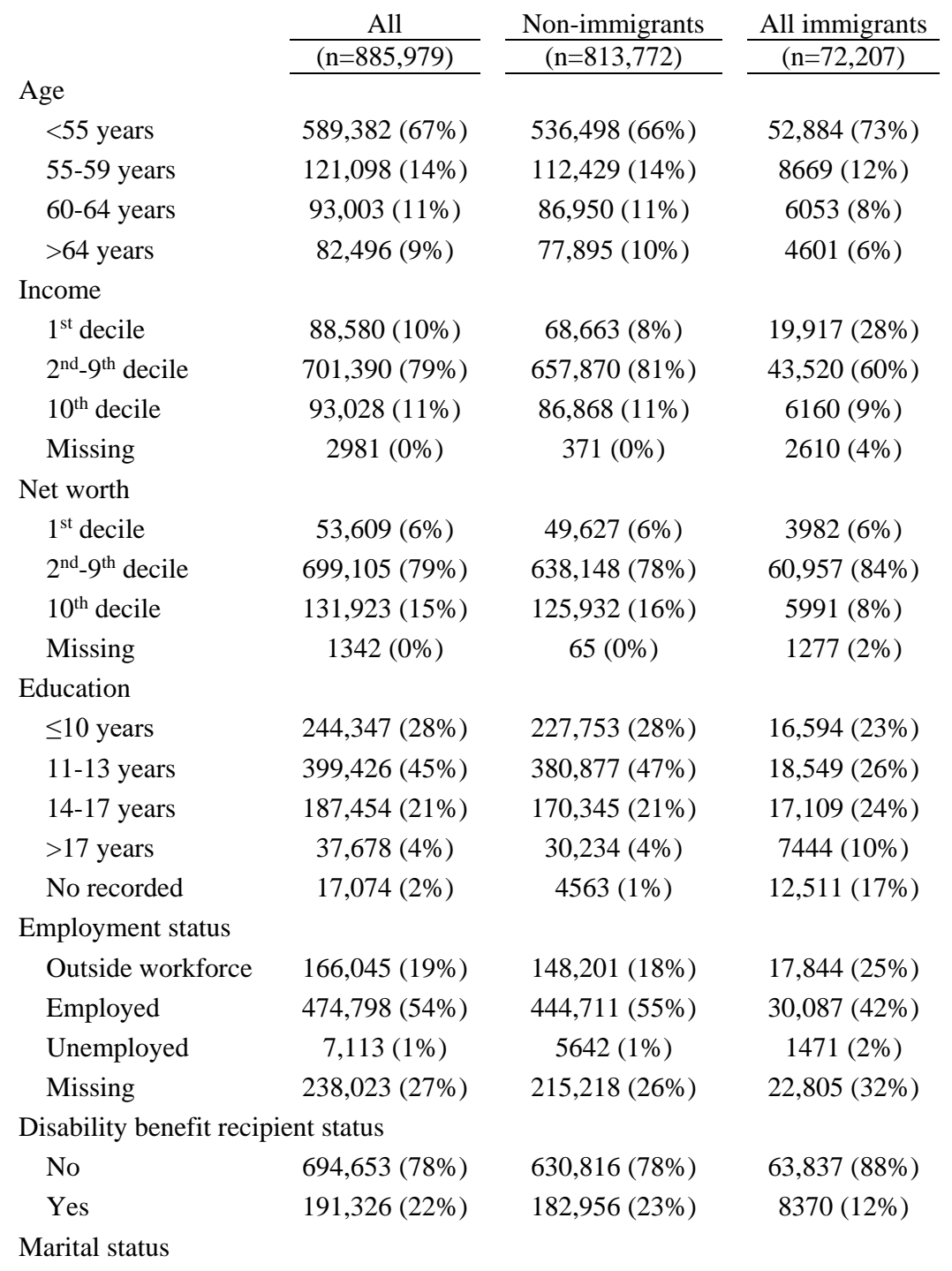




$\begin{array}{lccc}\text { Not married } & 86,989(10 \%) & 81,709(10 \%) & 5280(7 \%) \\ \text { Married/Partner } & 486,653(55 \%) & 445,133(55 \%) & 41,520(58 \%) \\ \text { Widow } & 137,979(16 \%) & 127,927(16 \%) & 10,052(14 \%) \\ \text { Separated } & 174,358(20 \%) & 159,003(20 \%) & 15,355(21 \%) \\ \text { Citizenship } & & & \\ \quad \text { Norwegian } & 848,114(96 \%) & 812,077(100 \%) & 36,037(50 \%) \\ \text { Other } & 37,865(4 \%) & 1695(0 \%) & 36,170(50 \%) \\ \text { Living in Oslo } & & & \\ \quad \text { No } & 779,184(88 \%) & 725,616(89 \%) & 53,568(74 \%) \\ \text { Yes } & 106,795(12 \%) & 88,156(11 \%) & 18,639(26 \%) \\ \text { Screening appointment } & & & \\ \text { year } & & & \\ \text { 1996-2005 } & 570,010(64 \%) & 536,770(66 \%) & 33,240(46 \%) \\ \text { 2006-2015 } & 315,969(36 \%) & 277,002(34 \%) & 38,967(54 \%) \\ \text { Years since immigration } & & & \\ <5 \text { years } & & & 17,038(24 \%) \\ \text { 5-9 years } & & & 7579(11 \%) \\ \text { 10-14 years } & & & 39,935(55 \%) \\ >14 \text { years } & & & 93(0 \%) \\ \text { Missing } & & & \end{array}$


Table 2: Screening attendance by socio-demographic factors for immigrant and non-immigrant women invited to attend BreastScreen Norway, $1996-2015$.

\begin{tabular}{|c|c|c|c|c|c|c|c|c|c|c|c|}
\hline & $\frac{\text { All }}{(74 \%)}$ & $\begin{array}{c}\begin{array}{c}\text { Non- } \\
\text { immigrants }\end{array} \\
(76 \%)\end{array}$ & $\begin{array}{c}\begin{array}{c}\text { All } \\
\text { immigrants }\end{array} \\
(53 \%)\end{array}$ & $\begin{array}{c}\text { Western } \\
\text { Europe } \\
(66 \%)\end{array}$ & $\begin{array}{c}\text { The Baltic } \\
\text { countries } \\
(32 \%)\end{array}$ & $\begin{array}{c}\text { Southern \& } \\
\text { Eastern } \\
\text { Europe } \\
(47 \%)\end{array}$ & $\begin{array}{c}\text { Northern } \\
\text { Africa \& } \\
\text { Western } \\
\text { Asia } \\
(41 \%)\end{array}$ & $\begin{array}{c}\text { Eastern } \\
\text { Africa } \\
(34 \%)\end{array}$ & $\begin{array}{l}\begin{array}{c}\text { Rest of } \\
\text { Africa }\end{array} \\
(53 \%)\end{array}$ & $\begin{array}{c}\begin{array}{c}\text { Rest of } \\
\text { Asia }\end{array} \\
(47 \%)\end{array}$ & $\begin{array}{c}\text { The } \\
\text { Americas } \\
\& \text { the } \\
\text { Pacific } \\
(55 \%)\end{array}$ \\
\hline \multicolumn{12}{|l|}{ Age } \\
\hline$<55$ years & $73 \%$ & $75 \%$ & $54 \%$ & $66 \%$ & $34 \%$ & $50 \%$ & $44 \%$ & $36 \%$ & $53 \%$ & $51 \%$ & $55 \%$ \\
\hline 55-59 years & $77 \%$ & $79 \%$ & $51 \%$ & $65 \%$ & $24 \%$ & $39 \%$ & $31 \%$ & $29 \%$ & $43 \%$ & $37 \%$ & $52 \%$ \\
\hline $60-64$ years & $77 \%$ & $79 \%$ & $50 \%$ & $68 \%$ & $27 \%$ & $35 \%$ & $28 \%$ & $23 \%$ & $65 \%$ & $31 \%$ & $53 \%$ \\
\hline$>64$ years & $74 \%$ & $75 \%$ & $52 \%$ & $70 \%$ & $38 \%$ & $36 \%$ & $24 \%$ & $23 \%$ & $54 \%$ & $26 \%$ & $63 \%$ \\
\hline \multicolumn{12}{|l|}{ Income } \\
\hline $1^{\text {st }}$ decile & $64 \%$ & $71 \%$ & $39 \%$ & $52 \%$ & $25 \%$ & $35 \%$ & $33 \%$ & $24 \%$ & $38 \%$ & $36 \%$ & $41 \%$ \\
\hline $2^{\text {ndd }}-9^{\text {th }}$ decile & $76 \%$ & $77 \%$ & $60 \%$ & $70 \%$ & $37 \%$ & $55 \%$ & $47 \%$ & $38 \%$ & $59 \%$ & $55 \%$ & $63 \%$ \\
\hline $10^{\text {th }}$ decile & $75 \%$ & $76 \%$ & $67 \%$ & $70 \%$ & $54 \%$ & $62 \%$ & $60 \%$ & $53 \%$ & $63 \%$ & $61 \%$ & $64 \%$ \\
\hline Missing & $25 \%$ & $31 \%$ & $25 \%$ & $35 \%$ & $11 \%$ & $20 \%$ & $23 \%$ & $25 \%$ & $29 \%$ & $21 \%$ & $21 \%$ \\
\hline \multicolumn{12}{|l|}{ Net worth } \\
\hline $1^{\text {st }}$ decile & $69 \%$ & $70 \%$ & $60 \%$ & $64 \%$ & $36 \%$ & $58 \%$ & $59 \%$ & $52 \%$ & $53 \%$ & $56 \%$ & $62 \%$ \\
\hline $2^{\text {nd }}-^{9^{\text {th }}}$ decile & $74 \%$ & $76 \%$ & $52 \%$ & $65 \%$ & $32 \%$ & $46 \%$ & $40 \%$ & $32 \%$ & $52 \%$ & $46 \%$ & $54 \%$ \\
\hline $10^{\text {th }}$ decile & $79 \%$ & $79 \%$ & $69 \%$ & $73 \%$ & $65 \%$ & $60 \%$ & $53 \%$ & $56 \%$ & $71 \%$ & $63 \%$ & $68 \%$ \\
\hline Missing & $25 \%$ & $32 \%$ & $25 \%$ & $32 \%$ & $17 \%$ & $20 \%$ & $26 \%$ & $28 \%$ & $42 \%$ & $24 \%$ & $22 \%$ \\
\hline \multicolumn{12}{|l|}{ Education } \\
\hline$\leq 10$ years & $70 \%$ & $72 \%$ & $52 \%$ & $67 \%$ & $41 \%$ & $47 \%$ & $44 \%$ & $32 \%$ & $54 \%$ & $48 \%$ & $56 \%$ \\
\hline 11-13 years & $77 \%$ & $78 \%$ & $60 \%$ & $69 \%$ & $33 \%$ & $50 \%$ & $49 \%$ & $49 \%$ & $62 \%$ & $56 \%$ & $62 \%$ \\
\hline $14-17$ years & $77 \%$ & $78 \%$ & $63 \%$ & $70 \%$ & $38 \%$ & $55 \%$ & $45 \%$ & $51 \%$ & $57 \%$ & $58 \%$ & $62 \%$ \\
\hline$>17$ years & $71 \%$ & $73 \%$ & $59 \%$ & $66 \%$ & $43 \%$ & $55 \%$ & $52 \%$ & $45 \%$ & $45 \%$ & $57 \%$ & $57 \%$ \\
\hline No recorded & $34 \%$ & $48 \%$ & $28 \%$ & $36 \%$ & $20 \%$ & $24 \%$ & $32 \%$ & $21 \%$ & $37 \%$ & $29 \%$ & $27 \%$ \\
\hline \multicolumn{12}{|l|}{ Employment status } \\
\hline Outside workforce & $63 \%$ & $66 \%$ & $43 \%$ & $57 \%$ & $29 \%$ & $39 \%$ & $39 \%$ & $26 \%$ & $38 \%$ & $41 \%$ & $46 \%$ \\
\hline Employed & $77 \%$ & $78 \%$ & $62 \%$ & $70 \%$ & $38 \%$ & $56 \%$ & $56 \%$ & $49 \%$ & $61 \%$ & $59 \%$ & $65 \%$ \\
\hline Unemployed & $61 \%$ & $65 \%$ & $46 \%$ & $54 \%$ & $30 \%$ & $46 \%$ & $52 \%$ & $27 \%$ & $45 \%$ & $45 \%$ & $47 \%$ \\
\hline Missing & $76 \%$ & $79 \%$ & $49 \%$ & $65 \%$ & $22 \%$ & $39 \%$ & $30 \%$ & $28 \%$ & $53 \%$ & $37 \%$ & $50 \%$ \\
\hline \multicolumn{12}{|c|}{ Disability benefit recipient status } \\
\hline No & $76 \%$ & $78 \%$ & $53 \%$ & $66 \%$ & $32 \%$ & $47 \%$ & $40 \%$ & $33 \%$ & $54 \%$ & $47 \%$ & $55 \%$ \\
\hline Yes & $69 \%$ & $70 \%$ & $57 \%$ & $68 \%$ & $75 \%$ & $52 \%$ & $45 \%$ & $44 \%$ & $46 \%$ & $49 \%$ & $60 \%$ \\
\hline
\end{tabular}


Marital status

Not married

Married/Partner

Widow

Divorced/Separated

Citizenship

Norwegian

Other

Living in Oslo

No

Yes

Screening appointment

year

Years since immigration

$<5$ years

5-9 years

10-14 years

$>14$ years

Missing

$\begin{array}{llllll}66 \% & 45 \% & 56 \% & 25 \% & 32 \% & 34 \% \\ 80 \% & 56 \% & 69 \% & 33 \% & 50 \% & 43 \% \\ 78 \% & 52 \% & 72 \% & 42 \% & 41 \% & 33 \% \\ 68 \% & 50 \% & 60 \% & 32 \% & 45 \% & 42 \% \\ 76 \% & 56 \% & 71 \% & 59 \% & 56 \% & 43 \% \\ 64 \% & 50 \% & 64 \% & 29 \% & 36 \% & 31 \% \\ 77 \% & 56 \% & 68 \% & 32 \% & 48 \% & 44 \% \\ 66 \% & 45 \% & 59 \% & 34 \% & 43 \% & 37 \% \\ & & & & & \\ 77 \% & 57 \% & 69 \% & 53 \% & 47 \% & 37 \% \\ 74 \% & 50 \% & 62 \% & 31 \% & 47 \% & 43 \% \\ & & & & & \\ & 34 \% & 43 \% & 25 \% & 32 \% & 30 \% \\ & 46 \% & 58 \% & 48 \% & 45 \% & 36 \% \\ & 53 \% & 66 \% & 53 \% & 55 \% & 45 \% \\ & 63 \% & 72 \% & 60 \% & 59 \% & 47 \% \\ & 76 \% & 79 \% & & 67 \% & 0 \%\end{array}$

$\begin{array}{llll}35 \% & 39 \% & 36 \% & 40 \% \\ 34 \% & 59 \% & 50 \% & 58 \% \\ 33 \% & 51 \% & 40 \% & 65 \% \\ 33 \% & 48 \% & 45 \% & 49 \% \\ & & & \\ 36 \% & 59 \% & 52 \% & 64 \% \\ 29 \% & 37 \% & 33 \% & 48 \% \\ & & & \\ 36 \% & 53 \% & 51 \% & 59 \% \\ 30 \% & 53 \% & 40 \% & 44 \% \\ & & & \\ 32 \% & 57 \% & 45 \% & 58 \% \\ 34 \% & 51 \% & 48 \% & 52 \% \\ & & & \\ 27 \% & 35 \% & 31 \% & 33 \% \\ 32 \% & 44 \% & 42 \% & 52 \% \\ 30 \% & 51 \% & 50 \% & 55 \% \\ 43 \% & 62 \% & 54 \% & 62 \% \\ & & 0 \% & 91 \%\end{array}$


Table 3: Multivariate analysis of attendance by socio-demographic factors for immigrant and non-immigrant women invited to attend BreastScreen Norway, $1996-2015$.

\begin{tabular}{|c|c|c|c|}
\hline & All & Non-immigrants & All immigrants \\
\hline \multicolumn{4}{|c|}{ 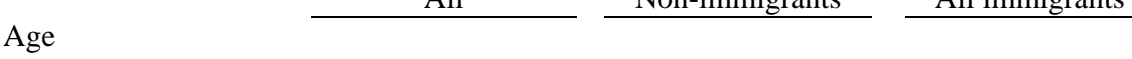 } \\
\hline$<55$ years & 1.00 (ref) & $1.00(\mathrm{ref})$ & $1.00(\mathrm{ref})$ \\
\hline $55-59$ years & $1.03(1.03-1.04)$ & $1.03(1.03-1.04)$ & $1.03(1.00-1.05)$ \\
\hline $60-64$ years & $1.06(1.05-1.06)$ & $1.06(1.05-1.06)$ & $1.03(1.00-1.06)$ \\
\hline$>64$ years & $1.05(1.04-1.05)$ & $1.04(1.03-1.04)$ & $1.06(1.03-1.09)$ \\
\hline \multicolumn{4}{|l|}{ Income } \\
\hline $1^{\text {st }}$ decile & 1.00 (ref) & $1.00(\mathrm{ref})$ & 1.00 (ref) \\
\hline $2^{\text {nd }}-9^{\text {th }}$ decile & $1.10(1.09-.1 .11)$ & $1.06(1.06-1.07)$ & $1.22(1.20-1.25)$ \\
\hline $10^{\text {th }}$ decile & $1.09(1.08-1.10)$ & $1.05(1.04-1.05)$ & $1.23(1.20-1.27)$ \\
\hline \multicolumn{4}{|l|}{ Net worth } \\
\hline $1^{\text {st decile }}$ & $1.00(\mathrm{ref})$ & $1.00(\mathrm{ref})$ & 1.00 (ref) \\
\hline $2^{\text {nd }}-^{\text {th }}$ decile & $1.05(1.05-1.06)$ & $1.06(1.05-1.06)$ & $1.01(0.98-1.04)$ \\
\hline $10^{\text {th }}$ decile & $1.08(1.08-1.09)$ & $1.08(1.07-1.08)$ & $1.06(1.03-1.10)$ \\
\hline \multicolumn{4}{|l|}{ Education } \\
\hline$\leq 10$ years & $1.00(\mathrm{ref})$ & $1.00(\mathrm{ref})$ & $1.00(\mathrm{ref})$ \\
\hline $11-13$ years & $1.07(1.07-1.07)$ & $1.07(1.06-1.07)$ & $1.09(1.07-1.11)$ \\
\hline $14-17$ years & $1.08(1.07-1.08)$ & $1.08(1.07-1.08)$ & $1.12(1.10-1.14)$ \\
\hline$>17$ years & $1.03(1.03-1.04)$ & $1.04(1.03-1.05)$ & $1.09(1.06-1.11)$ \\
\hline No recorded & $0.61(0.60-0.62)$ & $0.74(0.72-0.76)$ & $0.69(0.67-0.71)$ \\
\hline \multicolumn{4}{|l|}{ Employment status } \\
\hline Outside workforce & $1.04(1.02-1.06)$ & $1.03(1.01-1.05)$ & $0.95(0.90-1.01)$ \\
\hline Employed & $1.20(1.18-1.22)$ & $1.18(1.15-1.20)$ & $1.13(1.06-1.19)$ \\
\hline Unemployed & 1.00 (ref) & $1.00(\mathrm{ref})$ & 1.00 (ref) \\
\hline \multicolumn{4}{|c|}{ Disability benefit recipient status } \\
\hline No & $1.03(1.03-1.04)$ & $1.04(1.04-1.05)$ & $1.00(0.98-1.02)$ \\
\hline Yes & $1.00(\mathrm{ref})$ & $1.00(\mathrm{ref})$ & $1.00(\mathrm{ref})$ \\
\hline \multicolumn{4}{|l|}{ Marital status } \\
\hline Not married & 1.00 (ref) & $1.00(\mathrm{ref})$ & $1.00(\mathrm{ref})$ \\
\hline Married/Partner & $1.16(1.15-1.16)$ & $1.17(1.16-1.17)$ & $1.16(1.12-1.19)$ \\
\hline Widow & $1.12(1.11-1.13)$ & $1.13(1.13-1.14)$ & $1.09(1.05-1.13)$ \\
\hline Separated & $1.00(1.00-1.01)$ & $1.01(1.01-1.02)$ & $0.98(0.95-1.02)$ \\
\hline
\end{tabular}




\begin{tabular}{lccc}
\cline { 1 - 2 } $\begin{array}{l}\text { Norwegian } \\
\text { Other }\end{array}$ & $1.21(1.20-1.22)$ & $1.11(1.07-1.15)$ & $0.98(0.96-0.99)$ \\
Living in Oslo & $1.00(\mathrm{ref})$ & $1.00(\mathrm{ref})$ & $1.00(\mathrm{ref})$ \\
$\quad$ No & $1.22(1.21-1.22)$ & $1.20(1.19-1.20)$ & $1.22(1.20-1.24)$ \\
$\quad$ Yes & $1.00(\mathrm{ref})$ & $1.00(\mathrm{ref})$ & $1.00(\mathrm{ref})$ \\
$\begin{array}{l}\text { Screening appointment } \\
\text { year }\end{array}$ & & & \\
$\quad$ 1996-2005 & $1.00(\mathrm{ref})$ & $1.00(\mathrm{ref})$ & $1.00(\mathrm{ref})$ \\
$2006-2015$ & $0.99(0.98-0.99)$ & $1.00(0.99-1.00)$ & $0.96(0.94-0.97)$ \\
Years since immigration & & & $1.00(\mathrm{ref})$ \\
$\quad<5$ years & & & $1.07(1.03-1.11)$ \\
$5-9$ years & & & $1.22(1.18-1.26)$ \\
$10-14$ years & & & $1.33(1.29-1.37)$ \\
$>14$ years & &
\end{tabular}


Table 4: Multivariate analysis of attendance by socio-demographic factors for immigrant and non-immigrant women invited to attend BreastScreen Norway, 1996-2015, stratified by region of origin.

\begin{tabular}{|c|c|c|c|c|c|c|c|c|}
\hline & Western Europe & $\begin{array}{l}\text { The Baltic } \\
\text { countries }\end{array}$ & $\begin{array}{c}\text { Southern \& } \\
\text { Eastern Europe }\end{array}$ & $\begin{array}{l}\text { Northern Africa } \\
\& \text { Western Asia }\end{array}$ & Eastern Africa & Rest of Africa & Rest of Asia & $\begin{array}{c}\text { The Americas \& } \\
\text { the Pacific }\end{array}$ \\
\hline \multicolumn{9}{|l|}{ Age } \\
\hline$<55$ years & 1.00 (ref) & 1.00 (ref) & 1.00 (ref) & 1.00 (ref) & 1.00 (ref) & 1.00 (ref) & 1.00 (ref) & 1.00 (ref) \\
\hline $55-59$ years & $1.01(0.99-1.04)$ & $0.91(0.68-1.22)$ & $0.98(0.91-1.05)$ & $0.90(0.75-1.09)$ & $1.11(0.82-1.51)$ & $0.99(0.72-1.35)$ & $0.96(0.89-1.04)$ & $1.14(1.05-1.23)$ \\
\hline$>64$ years & $1.05(1.02-1.09)$ & $0.93(0.53-1.65)$ & $0.98(0.88-1.09)$ & $0.79(0.58-1.07)$ & $0.85(0.57-1.28)$ & $1.46(1.10-1.94)$ & $0.81(0.71-0.93)$ & $1.16(1.07-1.26)$ \\
\hline \multicolumn{9}{|l|}{ Income } \\
\hline $1^{\text {st }}$ decile & 1.00 (ref) & 1.00 (ref) & $1.00(\mathrm{ref})$ & 1.00 (ref) & 1.00 (ref) & 1.00 (ref) & 1.00 (ref) & 1.00 (ref) \\
\hline $2^{\text {nd }}-9^{\text {th }}$ decile & $1.16(1.12-1.20)$ & $1.25(1.01-1.53)$ & $1.21(1.14-1.27)$ & $1.22(1.11-1.35)$ & $1.31(1.09-1.57)$ & $1.28(1.01-1.61)$ & $1.21(1.16-1.27)$ & $1.23(1.15-1.33)$ \\
\hline $1^{\text {st }}$ decile & 1.00 (ref) & 1.00 (ref) & 1.00 (ref) & 1.00 (ref) & 1.00 (ref) & $1.00(\mathrm{ref})$ & 1.00 (ref) & 1.00 (ref) \\
\hline $2^{\text {nd }}-9^{\text {th }}$ decile & $1.06(1.02-1.10)$ & $1.48(0.84-2.61)$ & $1.01(0.94-1.07)$ & $0.85(0.73-0.97)$ & $0.93(0.76-1.15)$ & $1.10(0.86-1.40)$ & $1.00(0.94-1.06)$ & $0.96(0.89-1.05)$ \\
\hline $10^{\text {th }}$ decile & $1.08(1.03-1.13)$ & $1.70(0.89-3.24)$ & $1.01(0.93-1.11)$ & $0.87(0.70-1.07)$ & $1.01(0.74-1.39)$ & $1.19(0.86-1.64)$ & $1.10(1.03-1.18)$ & $1.04(0.94-1.14)$ \\
\hline \multicolumn{9}{|l|}{ Education } \\
\hline$\leq 10$ years & $1.00(\mathrm{ref})$ & $1.00(\mathrm{ref})$ & 1.00 (ref) & 1.00 (ref) & 1.00 (ref) & 1.00 (ref) & 1.00 (ref) & $1.00(\mathrm{ref})$ \\
\hline $11-13$ years & $1.02(0.99-1.05)$ & $0.93(0.71-1.22)$ & $1.06(1.01-1.11)$ & $1.11(1.00-1.23)$ & $1.35(1.15-1.58)$ & $1.05(0.89-1.23)$ & $1.10(1.05-1.14)$ & $1.08(1.01-1.15)$ \\
\hline Employed & $1.16(1.03-1.32)$ & $1.20(0.75-1.93)$ & $1.03(0.94-1.14)$ & $0.92(0.77-1.10)$ & $1.58(1.07-2.33)$ & $1.08(0.66-1.76)$ & $1.17(1.05-1.31)$ & $1.18(0.96-1.44)$ \\
\hline Unemployed & $1.00(\mathrm{ref})$ & 1.00 (ref) & $1.00(\mathrm{ref})$ & 1.00 (ref) & 1.00 (ref) & $1.00(\mathrm{ref})$ & 1.00 (ref) & 1.00 (ref) \\
\hline \multicolumn{9}{|c|}{ Disability benefit recipient status } \\
\hline No & $1.02(0.99-1.05)$ & $0.87(0.60-1.26)$ & $0.98(0.93-1.04)$ & $0.94(0.85-1.04)$ & $0.74(0.61-0.89)$ & $1.29(1.01-1.65)$ & $1.00(0.95-1.05)$ & $1.02(0.95-1.09)$ \\
\hline Yes & $1.00(\mathrm{ref})$ & 1.00 (ref) & $1.00(\mathrm{ref})$ & 1.00 (ref) & 1.00 (ref) & $1.00(\mathrm{ref})$ & $1.00(\mathrm{ref})$ & $1.00(\mathrm{ref})$ \\
\hline \multicolumn{9}{|l|}{ Marital status } \\
\hline Not married & 1.00 (ref) & 1.00 (ref) & 1.00 (ref) & 1.00 (ref) & 1.00 (ref) & 1.00 (ref) & 1.00 (ref) & $1.00(\mathrm{ref})$ \\
\hline Married/Partner & $1.13(1.10-1.17)$ & $1.15(0.90 .1 .46)$ & $1.34(1.21-1.48)$ & $1.14(0.87-1.50)$ & $1.06(0.85-1.31)$ & $1.41(0.98-2.02)$ & $1.30(1.16-1.45)$ & $1.27(1.13-1.43)$ \\
\hline Widow & $1.10(1.06-1.15)$ & $1.35(0.95-1.91)$ & $1.21(1.08-1.35)$ & $1.05(0.78-1.41)$ & $1.27(1.00-1.63)$ & $1.23(0.83-1.84)$ & $1.19(1.05-1.34)$ & $1.27(1.11-1.45)$ \\
\hline
\end{tabular}




\begin{tabular}{|c|c|c|c|c|c|c|c|c|}
\hline Separated & $0.99(0.96-1.03)$ & $1.06(0.81-1.38)$ & $1.13(1.02-1.26)$ & $0.99(0.75-1.31)$ & $0.91(0.72-1.14)$ & $1.09(0.75-1.59)$ & $1.09(0.97-1.22)$ & $1.01(0.90-1.15)$ \\
\hline \multicolumn{9}{|l|}{ Citizenship } \\
\hline Norwegian & $0.99(0.97-1.01)$ & $1.28(1.03-1.59)$ & $1.15(1.10-1.20)$ & $1.07(0.94-1.22)$ & $1.09(0.92-1.30)$ & $1.15(0.92-1.43)$ & $1.19(1.13-1.25)$ & $1.14(1.09-1.20)$ \\
\hline Other & 1.00 (ref) & 1.00 (ref) & 1.00 (ref) & 1.00 (ref) & 1.00 (ref) & 1.00 (ref) & 1.00 (ref) & 1.00 (ref) \\
\hline \multicolumn{9}{|l|}{ Living in Oslo } \\
\hline No & $1.17(1.14-1.20)$ & $1.12(0.85-1.48)$ & $1.16(1.10-1.21)$ & $1.14(1.04-1.24)$ & $1.25(1.09-1.42)$ & $0.97(0.84-1.11)$ & $1.19(1.15-1.23)$ & $1.27(1.19-1.35)$ \\
\hline Yes & 1.00 (ref) & 1.00 (ref) & 1.00 (ref) & 1.00 (ref) & 1.00 (ref) & 1.00 (ref) & 1.00 (ref) & 1.00 (ref) \\
\hline \multicolumn{9}{|c|}{$\begin{array}{l}\text { Screening appointment } \\
\text { year }\end{array}$} \\
\hline $1996-2005$ & 1.00 (ref) & 1.00 (ref) & 1.00 (ref) & 1.00 (ref) & 1.00 (ref) & 1.00 (ref) & 1.00 (ref) & 1.00 (ref) \\
\hline 2006-2015 & $1.01(0.99-1.04)$ & $0.86(0.63-1.17)$ & $1.00(0.96-1.05)$ & $0.85(0.77-0.94)$ & $0.97(0.82-1.16)$ & $1.09(0.90-1.33)$ & $0.96(0.92-0.99)$ & $1.02(0.96-1.08)$ \\
\hline \multicolumn{9}{|c|}{ Years since immigration } \\
\hline$<5$ years & 1.00 (ref) & 1.00 (ref) & 1.00 (ref) & 1.00 (ref) & 1.00 (ref) & 1.00 (ref) & 1.00 (ref) & 1.00 (ref) \\
\hline $5-9$ years & $1.09(1.02-1.15)$ & $1.38(1.15-1.66)$ & $1.04(0.97-1.11)$ & $0.95(0.81 .1 .12)$ & $0.83(0.67-1.04)$ & $0.99(0.67-1.46)$ & $0.90(0.83-0.98)$ & $1.08(0.95-1.24)$ \\
\hline $10-14$ years & $1.21(1.14-1.28)$ & $1.30(0.98-1.73)$ & $1.16(1.09-1.24)$ & $1.16(1.00-1.35)$ & $0.75(0.59-0.94)$ & $1.12(0.79-1.57)$ & $1.02(0.95-1.10)$ & $1.11(0.97-1.26)$ \\
\hline$>14$ years & $1.26(1.21-1.32)$ & $1.34(1.01-1.79)$ & $1.24(1.17-1.32)$ & $1.19(1.03-1.36)$ & $0.86(0.71-1.05)$ & $1.30(0.96-1.77)$ & $1.02(0.96-1.09)$ & $1.14(1.02-1.27)$ \\
\hline
\end{tabular}

